\title{
MATERNIDADE NA ADOLESCÊNCIA: sonho realizado e expectativas quanto ao futuro ${ }^{\mathrm{a}}$
}

\author{
Paula Rosenberg de ANDRADE ${ }^{b}$ \\ Circéa A malia RIBE IROC \\ Conceição Vieira da Silva OHARAc
}

\section{RESUMO}

Estudo qualitativo que objetivou descrever os motivos que impulsionam a adolescente a engravidar e quais suas expectativas quanto ao futuro, após o nascimento do filho. 0 Interacionismo Simbólico foi referencial teórico e a Teoria Fundamentada nos Dados, o referencial metodológico. Participaram oito mães adolescentes, de 15 a 19 anos de idade, que vivenciavam a experiência de cuidar dos filhos. As estratégias utilizadas de coleta de dados foram observação participante e entrevista semi-estruturada. A análise dos dados evidenciou que tor nar-se mãe é uma experiência que pode ser desejada e até planejada, e que, após o nascimento do bebê, a adolescente continua a ter expectativas de realizações visando proporcionar um futuro melhor para si e seu filho, conforme revelado nas categorias: Realizando um sonho, eT endo expectativas quanto ao futuro. A compreensão dessa vivência contribuirá na prática dos profissionais que assistem gestantes e mães adolescentes, nos diferentes níveis de atenção.

D escritores: A dolescente. G ravidez na adolescência. Relações mãe-filho. Relações familiares.

\section{RESUMEN}

E studio cual itativo, que tuvo como objetivo describir los motivos que impul san a la adol escentea embarazarse y cuáles son sus expectativas en cuanto al futuro, después del nacimiento del hijo. EI refer encial teórico fue el Interaccionismo Simbólico y la T eoría $\mathrm{F}$ undamentada en los $\mathrm{D}$ atos, el referencial metodológico. Participaron en el estudio ocho madres adolescentes, de 15 a 19 años de edad, quevivenciaban la experiencia de cuidar a los hijos. L as estrategias utilizadas de recolección dedatos fueron la observación partici pante y la entrevista semi-estructurada. El análisis de los datos evidenció que convertirse en madre es una experiencia que puede ser deseada y hasta planificada y que después del nacimiento del bebé la adolescente continúa teniendo expectativas de realizaciones visando proporcionar un futuro mejor para sí misma y para su hijo, confor me revelado en las categorías: R ealizando un sueño y T eniendo expectativas en cuanto al futuro. L a comprensión de esa vivencia contribuirá en la práctica de los profesionales que asisten a gestantes y madres adolescentes, en los diferentes nivel es de atención.

D escriptores: Adolescente. E mbarazo en adolescencia. R elaciones madre hijo. R elaciones familiares.

T ítulo: $L$ a maternidad en la adolescencia: sueño realizado y las expectativas para el futuro.

\section{ABST RACT}

This qual itativestudy aimed at describing the reasons that motivate an adolescent to get pregnant and her expectations about the future after the child's birth. Symbolic Interactionism was used as theoretical framew ork and G rounded Theor $y$ as the methodological one. E ight adolescent mothers aged between 15 and 19 years who lived the experience of caring for their children took part in the study. Data collection tools were observant participation and semi-structured interviews. D ata analysis revealed that becoming a mother is an experiencethat might be desired and even planned. F urther more, data show ed that after the child's birth, the adolescent continues to have expectations of self-realization in order to providea better future for herself and for her child, as revealed by the categories: $\mathrm{M}$ aking a dream come true and $\mathrm{H}$ aving expectations about the future The full understanding of this experience will contributeto the practice of all professionals that provideassistance to pregnant and adol escent mothers at different levels of healthcare.

D escriptors: Adolescent. P regnancy in adolescence. M other-child relations. Family relations. $T$ itle: $M$ aternity in adolescence: a dream come true and future expectation.

\footnotetext{
a Artigo originado da dissertação de M estrado apresentada em 2004 ao Programa de Pós-Graduação em Enfermagem da U niversidade Federal de São Paulo (U NIFESP).

${ }^{b}$ M estre em Ciências, D outoranda do Programa de Pós-G raduação em Enfermagem da U NIF ESP, Enfermeira do Centro Assistencial Cruz de M alta, São Paulo, Brasil

c D outora em Enfermagem, Professora A ssociada do D epartamento de Enfermagem da U NIFESP, São Paulo, Brasil.
} 


\section{INT RODUÇÃO}

A Organização M undial da Saúde define a adolescência como o período de vida no qual o indivíduo passa do aparecimento das características sexuais secundárias à maturidade; aquel e cujos padrões psicológicos e a identificação do indivíduo evoluem da fase infantil à adulta ${ }^{(1)}$. É um período caracterizado por inúmeras transformações que marcam esse complexo momento de transição, que pode se tor nar ainda mais difícil quando ocorre uma gravidez, pois quando a adolescente engravida e torna-se mãe, ela interrompe o curso natural de sua idade e começa a deparar-se com inúmer as responsabilidades em um momento que está emaranhada em um turbilhão de transfor mações ${ }^{(2)}$.

A ocorrência da gravidez na adolescência é frequentemente descrita como sendo acompanhada por forte estresse em razão das inseguranças típicas da idade, que o mesmo está diretamente relacionado a vários problemas adversos de ordem psicofísica e social, tais como: fal ta de apoio ou abandono do pai da criança, falta de apoio da família, inter rupção nas atividades de lazer e evasão escolar, levando a um grave problema socioeconômico que poderá acompanhar essa adol escente pelo resto de sua vida(3,4).

Esta problemática converteu-se em um dos grandes problemas de saúde pública(2), não só pelo significativo número de adolescentes grávidas ${ }^{(5,6)}$, como devido às diversas repercussões deste fenômeno na vida desta menina, pois além dos riscos biológicos para a mãe e a criança, a gravidez na adolescência também traz transtornos emocionais e econômicos para o núcl eo familiar onde ela ocorre ${ }^{(4)}$. A inter rupção do processo de formação dessa jovem, que muitas vezes é obrigada a deixar a escola, é excluída do mercado de trabal ho e a fal ta de apoio dos familiares e amigos, entre outros, são alguns dos dilemas que as adolescentes são obrigadas a enfrentar quando se vêem à espera de um filho(7).

Como enfermeiras docentes e assistenciais, temos atendido um número expressivo de mães adolescentes que buscam a consulta de enfermagem em puericultura para seguimento de seus fiIhos no ambulatório onde atuamos. A situação nos despertou um interesse maior e mais aprofundado pela temática, pois começamos a interagir quase diariamente com essas adolescentes, seus filhos, suas histórias de vida e pudemos perceber quantas ansiedades, medos e inseguranças permeiam esse momento.

T ais inquietações fizer am com que buscássemos uma melhor compreensão das demandas de apoio da mãe adolescente para cuidar de seu fiIho. Assim, realizamos uma pesquisa que objetivou compreender o significado de cuidar do filho para a mãe adolescente ${ }^{(8)}$, na qual emergiram várias categorias temáticas representativas dos diferentes aspectos da vivência investigada, entre as quais destacaremos, neste trabal ho, Realizando um sonho e T endo expectativas quanto ao futuro.

E mbora as publicações sobre a temática descrevam a gestação da adolescente como não planejada, indesejada e responsável pela ruptura de suas expectativas e aspirações de seus planos futuros ${ }^{(7,9)}$, os dados dessas categorias evidenciaram uma realidade diferente: as mães adolescentes pesquisadas mencionaram ter planejado a gravidez, que seus sonhos não terminaram, continuam após o nascimento do bebê e que esses giram em torno de meIhorar sua vida, com a intenção de proporcionar 0 que há de melhor ao seu filho. E $\mathrm{m}$ face dessas considerações, o presente artigo tem como objetivo descrever os motivos que impulsionam a adolescente a engravidar e quais são suas expectativas quanto ao futuro, após o nascimento do filho.

\section{METODOLOGIA}

Trata-se de recorte de uma pesquisa qualitativa que utilizou como referencial teórico o Interacionismo Simbólico (IS) que se constitui em uma perspectiva de análise das experiências humanas que têm como foco de estudo a natureza da interação ${ }^{(10)}$. 0 referencial metodológico foi a T eoria F undamentada nos Dados (TFD) - G rounded Theory, que se propõe ao desenvolvimento de teorias geradas a partir dos dados obtidos e analisadas de forma sistemática, comparativamente, em um processo não-linear, no decorrer da própria pesquisa ${ }^{(11,12)}$.

0 estudo foi realizado no Ambulatório de Consulta de Enfermagem do Centro Assistencial Cruz de M alta (CACM), instituição filantrópica não-governamental da cidade de São Paulo, que mantém um Programa de Integração DocenteA ssistencial com o D epartamento de E nfer magem da U niversidade Federal de São Paulo ${ }^{(13)}$.

Participaram oito mães adolescentes de 15 a 19 anos de idade, que constituíram três grupos 
amostrais. 0 primeiro compreendeu três mães adolescentes de 19, 16 e 15 anos de idade, que haviam tido seus filhos aos 15 anos, apresentavam histórias de abandono e maus-tratos na infância, abandono do companheiro durante a gravidez ou após o nascimento da criança, sérios problemas na dinâmica familiar, abandono da escola e grandes dificuldades financeiras.

0 segundo constituiu-se de duas mães adolescentes de 16 e 17 anos de idade que, embora também fossem de uma condição socioeconômica pouco favorecida, vivenciaram o apoio da família na infância, durante a gravidez e após o nascimento de seus filhos, além do que moravam com os companheiros.

0 terceiro foi composto de três mães adolescentes: uma teve o filho com 19 anos de idade e, na época da coleta de dados, estava com 22 anos; a segunda teve o filho com 15 anos de idade e estava com 19 e a terceira tinha 17 anos de idade. As três provinham de uma estrutura familiar mais sólida, com bases educacionais e condições econômicas mais estáveis e favorecidas.

Com relação aos aspectos éticos, este estudo observou as diretrizes da Resolução 196/ 96 do Conselho Nacional de Saúde ${ }^{(14)}$, sendo aprovado pelo Comitê de Ética e Pesquisa da U niversidade Federal de São Paulo (U N IFESP) sob o parecer $n$ 으 0562/02. As participantes da pesquisa foram esclarecidas sobre as finalidades, os objetivos e a metodologia do estudo, sendo assinado Termo de Consentimento Livre e Esclarecido, o qual também foi assinado pelo adulto responsável pelas menores de 18 anos. Às participantes, foi garantido 0 anonimato sobre sua identidade, bem como o esclarecimento que julgasse necessário antes ou no decorrer da pesquisa. Foi assegurado também a liberdade de se recusarem a participar ou retirarem seu consentimento em qualquer fase da pesquisa, sem nenhum ônus à criança, adolescente ou família.

As estratégias utilizadas na coleta de dados foram a observação participante e a entrevista semiestruturada. A primeira ocorreu na consulta de enfer magem ou na residência da mãe, com o objetivo de se observar como a mãe adolescente interagia com o filho durante a prestação dos cuidados, com os membros da família e com o profissional de saúde.

As entrevistas, realizadas no CACM ou na residência das mães, foram gravadas e, posterior- mente, transcritas na íntegra, sendo iniciadas com a seguinte questão norteadora: "Conte-me, como está sendo para vocêa experiência de cuidar de seu filho?". Durante seu desenrolar, outras questões iam sendo formuladas, buscando aprofundar a compreensão do que estava sendo narrado pela mãe.

Os dados foram analisados concomitantemente à coleta, conforme preconizado pela T FD, obedecendo aos passos previstos pela metodologia: codificação inicial ou aberta; categorização; codificação teórica; identificação da categoria central e a construção e validação do modelo teórico representativo da experiência ${ }^{(11,12)}$.

As categorias que são objeto deste trabal ho, assim como as subcategorias que as compõem serão descritas e exemplificadas com falas extraídas dos discursos das mães adolescentes participantes e identificadas com as letras iniciais M A e seu respectivo número: 1, 2, 3 e, assim, sucessivamente.

\section{RESULT ADOS}

\section{Realizando um Sonho}

A categoria Realizando um Sonho revela a intenção consciente e desejada da adolescente tornar-se mãe, expressando seu desejo de ter um filho que, muitas vezes, se apresenta como um projeto de vida. A ssim, ela vai construindo suas ações em direção àquilo que almeja: ser mãe e preparar-se para tal. N este caminhar, el a revê experiências passadas, tanto positivas como negativas, de como foi cuidada, conforme revelam as subcategorias: Querendo ser mãe, Permitindo-se ser mãe, Preparando-se para ser mãe, e Revivendo experiências passadas.

\section{Querendo ser mãe}

0 desejo de ser mãe impulsiona a adolescente a vivenciar essa experiência em sua concretude, 0 que faz com que ela planeje sua gravidez, ou, não tome precauções para que a mesma não ocorra. A lgumas vezes, a emergência de ter um filho pode ser influenciada pelo companheiro, o que faz aflorar a vontade, do que não era planejado para aquele momento.

[ ... ] A verdadeéque eu não imaginava muita coisa, 0 fato era que eu queria ser mãe e ponto final, o resto era conseqüência (M A 1). 
E le sempre quis ter um filho, desdea época quea gente namorava. E u semprefalava quenão queria. Aí a gentefoi morar junto, eeu parei deusar o preservativo. F oi porque eu quis engravidar, né? (M A2).

Permitindo-se ser mãe

O utras vezes, o desejo de ser mãeé vivenciado de maneira ambígua pela mãe adolescente, pois ela refere que não queria ser mãe ainda, mas não vinha tomando as devidas precauções para não engravidar. Ela ainda atribui significados de loucura e irresponsabilidade à ocorrência de tal fato, porém, ao mesmo tempo, jul ga ser "bem legal" ser mãe adolescente.

$\mathrm{N}$ ão, eu não queria ser mãe, aconteceu. $\mathrm{E} u$ acho bem legal ser mãe adolescente. $\mathrm{E}$ u nunca tomei nada e não estava tomando nada. E u achava que nada ia acontecer comigo. E u acho quefoi loucura eir responsabilidade, não foi planejado, mas aconteceu (M A 3).

\section{Preparando-se para ser mãe}

Esta subcategoria retrata a preocupação da mãe adolescente buscar cursos e palestras que a ajudem e a capacitem a cuidar de seu filho, ainda durante a gravidez. A busca é impulsionada pelo medo de não vir a ser boa mãe, de não conseguir cuidar de seu filho e ainda de ser julgada irresponsável, pelo fato de ser mãe adolescente.

E u tive medo assi $m$ denão demonstrar responsabilidade e de não conseguir cuidar dela sozinha. No começo tive muito medo das pessoas ol harem efal arem: nossa! E la tem dificuldade em cuidar e não tem responsabilidade. $\mathrm{E} u$ acho queé por isso que, quando eu estava grávida, procurei me informar, fazer cursos de gestantes, fui a palestras. E u acho que eu tinha tanto medo do que poderia vir a acontecer e ainda das pessoas falarem: nossa! E la tem 16 anos e não sabe cuidar bem de seu filho (M A 4).

\section{Revivendo experiências passadas}

A o real izar esse sonho, a mãe adolescente começa a interagir com lembranças relacionadas à sua infância, revivendo vivências da época, ou mesmo, da gravidez como o fato de ter sido abandonada, violentada ou rejeitada pela família, reativando lembranças, mágoas e ressentimentos. Por outro lado afloram lembranças positivas de amor, carinho, atenção e cuidados.
M inha mãe nunca ligou pra mim; E la sempre ligou mais para os meus irmãos pequenos que são fil hos do segundo casamento dela com meu padrasto. E aí, com 10 anos, fui morar com ela. M inha avó me mandou morar com ela, aí eu fui. E les moravam em D iadema. Com 10 anos, ele tentou me estupra; E la a pareceu e ele falou que eu queria ter relações com ele Ai, ela me bateu eaí eu voltei pra casa da minha avó; M inha avó me pegou de volta (M A5).

Sabe, quando eu nasci, minha mãetrabal hava. E u sempre fiquei com a minha avó, mãe da minha mãe; $E$ la sempre me deu atenção e carinho. E ntão, nunca faltou amor e carinho, então, cuidar pra mim éisso, e éisso que eu vou tentar passar pro meu filho (M A 4).

\section{T endo Expectativas Q uanto ao F uturo}

A pós o nascimento do filho, interagindo com as demandas que o cuidar exige, a mãe adolescente vai refletindo que estudar e trabalhar implica ter garantias de um futuro melhor para si e a seu fiIho.

A ssim, a categoria T endo Expectativas Quanto ao F uturo revela dados que per mitem compreender que, após o nascimento do filho, a mãe adolescente continua a ter sonhos, ela não os interrompe: planeja estudar, trabal har e investir na qualidade da relação mãe-filho, com a determinação de que seu filho não passará pelo que ela passou e que terá nela al guém com quem vai poder contar sempre. Estas expectativas estão expressas nas subcategorias: Querendo estudar, Querendo trabalhar, I nvestindo na qualidade da relação mãe-filho, e Almejando um futuro melhor para 0 filho.

\section{Querendo estudar}

A mãe adolescente não quer interromper os estudos, pois reconhece que estes trarão oportunidades para que nada fal te ao filho, para que ela possa vir a ter um futuro melhor. Expressa a vontade de cursar uma faculdade e ser uma profissional, o que Ihe proporcionará autonomia financeira e reverter-se-á em benefícios para si e a seu filho.

E u quero estudar para melhorar as coisas pra mim e pro meu filho (M A5).

E u não parei de estudar, eu penso em fazer uma faculdade e cada vez melhorar as coisas em relação a meu filho (MA1). 
Querendo trabalhar

Esse anseio ocorre em razão da adolescente interagir com as novas demandas, provenientes das exigências para cuidar do filho. A mãe adolescente quer trabalhar, garantir seu próprio sustento e, assim, poder dar as coisas ao filho, sem depender de outros.

E u queria trabal har porque, assi $m$, eu não ia depender de ninguém para me ajudar, da minha madrinha, da minha mãe (M A 6).

Investindo na qualidade da relação mãe-filho

A lém de querer voltar a estudar e trabalhar, a mãe adol escente preocupa-se com seu desempenho materno. Ela quer participar ativamente da educação e cuidados do filho, quer ser reconhecida como mãe e ainda ocupar seu papel na totalidade. A credita que, no futuro, terá um bom relacionamento com o filho se souber cuidá-lo e fizer tudo por ele. E la quer que 0 filho a reconheça como amiga, conselheira, alguém em que possa confiar, que seja única e acredita que el e cuidará dela, com o mesmo zelo e responsabilidade como foi cuidado.

Ela ainda define para si que aquilo que se planta é o que se irá colher e, nesse sentido, quer plantar amor e colher, como fruto, o amor do filho.

P rimeiro, eu quero ser a mãe dela e não a outra; ser uma mãezona, quero dar atenção, carinho, coisas que eu não tive (M A 5).

$\mathrm{E} u$ acho que a gente colhe aquilo que a gente planta, pra minha filha, eu estou plantando amor (M A4).

Almejando um futuro melhor ao filho

A lém de investir na qualidade da relação mãefilho, a mãe adolescente tem expectativas e preocupa-se quanto ao futuro do filho, esperando que el e tenha a gar antia de estudo, educação e cultura. E spera também que tenha respeito pelos mais veIhos; pretende vê-lo longe do mundo das drogas; que seja uma pessoa trabal hadora e honesta e deseja protegê-lo das dores e decepções da vida. Ela não deseja que ele passe pelos sofrimentos pelos quais passou.

[ ...] eu quero que ela estude, quero ter meios pra dar curso pra ela, eu quero que ela seja estudiosa, que tenha cul tura, que tenha futuro eque pense no futuro, que não pense em ficar preguiçosa, eu não quero isso (M A 7).

[ ...] para ela, ter uma experiência de vida através de minha vida, sabe? E la também ser uma pessoa madura, poder dar conselho pra al guma amiga. $N$ ão quero que ela passe pel o que eu passei que, meu ex emplo, possa servir pra ela, entendeu? (M A8).

\section{DISCUSSÃO}

Os achados deste estudo, obtidos e analisados com base nas premissas do IS e da TFD permitiram compreender os motivos que impulsionam a adolescente a engravidar e quais as expectativas quanto a seu futuro e de seu filho.

$U \mathrm{~m}$ dos aspectos evidenciados é o fato de que a adol escente, ao eng ravidar, pode estar R ealizando um Sonho, decisão que contempla não apenas um ato biológico reprodutivo, mas, um processo social envolvendo interações com familiares, seu companheiro e, ainda, a vontade de vir a ser mãe e ingressar no mundo adulto que a faz ser reconhecida, além de reforçar sua condição feminina de ser mulher e mãe.

A liter atura aponta que a gravidez na vida de uma mulher não se verifica de modo aleatório e sim por prioridades preestabelecidas, isto é, elaboração de planos, projetos ou pela concretização da prática sexual, já que conhecem os métodos contraceptivos para evitar a gravidez ${ }^{(2)}$. E studos indicam que, para al gumas adolescentes, 0 desejo consciente ou não de ter um filho representa um momento no qual revivem experiências passadas, ressignificando-as e levando-as a pensar em como poderão proporcionar um futuro melhor a seu filho. Reforçam que 0 anseio de ser mãe na adolescência pode significar realização e felicidade por ser fruto de um momento de prazer e desejo $0^{(15,16)}$.

N este sentido, pesquisa realizada com 598 adolescentes australianas encontrou que $77 \%$ delas referiram ter planejado e tomado a decisão de engravidar ${ }^{(17)}$. Outro estudo, realizado com 1.500 adolescentes inglesas, de 13 a 18 anos de idade, constatou que embora apenas $9 \%$ delas asseguraram querer engravidar as demais não tomaram as devidas precauções para que a gravidez não ocorresse ${ }^{(18)}$, em concordância com os depoimentos das adolescentes que foram sujeitos desta pesquisa. 
E ste achado também concorda com os de outras pesquisas brasileiras realizadas com as adolescentes ainda gestantes, que relataram ter planejado eng ravidar, apresentarem várias expectativas quanto ao futuro e idealizarem atitudes positivas que revertessem em mel hores cuidados para si e a seus filhos ${ }^{(19)}$.

Há estudos que se contrapõe a esses, um deles advertindo sobre a fal ta de expectativas e a vida limitada da gestante adolescente, conotando que seus sonhos foram interrompidos e que passam a ser donas de casa e a cuidar dos filhos, assim que sabem de sua gravidez ${ }^{(9)}$.

A ssim, a categoria T endo expectativas quanto ao futuro revela dados que não só contradizem esses achados, como o discurso do senso comum a respeito da falta de expectativas, decorrentes da mater nidade precoce, permitindo compreender que os sonhos e as expectativas de vida da adolescente continuam a existir, após o nascimento do filho.

Vale ressaltar que a família representa um papel primordial para que a mãe adol escente concretize tais sonhos, já que funciona como um importante elemento facilitador para que essa mãe sinta-se mais tranquila, fortal ecida e supere os obstáculos nos cuidados do filho.

0 apoio da família é imprescindível para dar o suporte financeiro, ajudar nos cuidados diários à criança, a fim de proporcionar à mãe adolescente momentos de descanso e, para que vivencie o cuidar de seu filho de forma mais tranquila, conforme suas possibilidades financeiras. 0 suporte familiar, também, favorece oportunidades, para que possa concretizar seus planos futuros que continuam a existir ${ }^{(8)}$

Outros estudos revelam que mães adolescentes que obtiveram ajuda frequente e assistência no cuidado de seus filhos, advindas de suas mães e avós, sogros e companheiros evidenciaram maior motivação para dar continuidade aos estudos, trabalhar, além de manter o contato com os amigos ${ }^{(19,20)}$. Esta questão é mer ecedora de atenção por parte dos profissionais de saúde, pois a família seguramente proporciona o suporte para que a adolescente dê continuidade a seus projetos de vida e, portanto, deve ser contemplada no plano assistencial da enfermagem como cliente.

\section{CONSIDERAÇÕES FINAIS}

Acreditamos que os objetivos do estudo foram alcançados, uma vez que foram apresenta- dos e discutidos os dados das duas categorias da pesquisa refer entes ao sonho de ser mãe e à manutenção das expectativas e planos futuros das adolescentes pesquisadas.

E speramos que tais achados contribuam para a prática dos profissionais de saúde que assistem gestantes e mães adolescentes nos diferentes níveis de atenção. Para tal, acreditamos ser responsabilidade desse profissional manter um canal de comunicação per manentemente aberto e estabelecer um relacionamento terapêutico de confiança, livre de preconceitos, oferecendo às adolescentes subsídios para que, se optarem por engravidar, o façam com consciência dos custos financeiros, sociais, emocionais e das responsabilidades que o cuidar do filho acarretam.

A lém disso, o respeito à decisão de ser mãe contribui para proporcionar uma outra postura em relação ao que é ser mãe adolescente, pois sendo esta uma opção dela, acertada ou não, devemos procurar entender as circunstâncias de vida que a levaram a querer ter um filho e estabelecer condições para que cuide dele com todas as suas potencialidades.

0 grande desafio é instituirmos medidas de apoio e estímulos educativos e socioculturais extensivos para que resgate a importância da ajuda de suas famílias, assim como dê continuidade a seus projetos de vida, como seu retorno à escola. Para tanto, uma das estratégias propostas pode ser a realização de oficinas que levem à promoção da relação dessa adolescente-mãe consigo mesma, procurando trabalhar positivamente sua identidade, autoestima, autodeterminação autocuidado e autoconfiança. A inda como estratégia de prevenir a gravidez na adolescência, pode-se pensar na formação de grupos de jovens com a presença de gestantes e mães adol escentes, a fim de discutir as perdas que podem ocorrer em decorrência de uma gravidez precoce e as demandas que as mesmas acarretam.

Gostaríamos ainda de ressaltar que este estudo foi realizado com mães adolescentes que experenciaram a maternidade e o cuidado do filho na faixa etária de 15 a 19 anos de idade, de modo que a vivência das adolescentes de 10 a 14 anos de idade pode não ser a mesma aqui revelada e necessita ser explorada por meio de novos estudos. N esse sentido, estamos realizando uma pesquisa com mães adolescentes dessa faixa etária. 


\section{REFERÊ NCIAS}

1 Organización M undial de la Salud. La salud de los jóvenes: un reto y una esperanza. G inebra; 1995.

2 T akiuti AD. U topia? A nálise de um modelo de atenção integral à saúde do adolescente no Sistema Ú nico de Saúde do Estado de São Paulo. Rio de Janeiro: A rtes e Contos; 2001.

3 Heilborn M L, Aquino EM L, Bozon M, Knauth DR, organizadores. 0 aprendizado da sexualidade: reprodução e trajetórias sociais de jovens brasileiros. R io de Janeiro: G aramond/ Fiocruz; 2006.

4 Lage AM D. Vivências da gravidez de adolescentes [ tese] . Bel o H orizonte: E scola de Enfer magem, U niversidade F ederal de M inas G erais; 2008.

5 M inistério da Saúde (BR). Pesquisa nacional de demografia e saúde. Brasília (DF ); 2008.

6 Chagas NR, M onteiro AR M. A relação entra a mãe adolescente e 0 bebê pré-ter mo: sentimentos desvelados. Rev Gaúcha Enferm. 2007;28(1):35-44.

7 Pantoja AL N. "Ser alguém na vida": uma análise sócio-antropológica da gravidez/ maternidade na adolescência, em Belém do Pará, B rasil. Cad Saúde Pública. 2003;19(Supl 2):S335-43.

8 Andrade PR. Superando dificuldades impulsionadas pela força do amor: a experiência da mãe adolescente vivenciando o cuidado do filho [ tese]. São Paulo. E scola de Enfermagem, Universidade Federal de São Paulo; 2004.

9 T rindade RF C. Entre o sonho e a realidade: a maternidade na adolescência sob a ótica de um grupo de mulheres da periferia da cidade de M aceió-AL. Rev E letrônica E nferm [ I nternet] . 2007 [ citado 2009 dez 16] ;9(1):277-8. Disponível em: http:/ / www.fen.ufg. br/ revista/ v9/ n1/ v9n1a23.htm.

10 Charon JM. Simbolic Interacionism: an introduction, an interpretation and integration. $3^{\text {rd }}$ ed. N ewJersey: Prentice-Hall; 1989.
11 Glaser BG. Theorical sensivity. M ill Valley: The Sociology; 1978.

12 Strauss AL, Corbin J. Basic of qualitative research: grounded theory procedures and techniques. $\mathrm{New}$ York: Sage; 1990.

13 Ribeiro CA, Silva CV, Saparolli ECL. Consulta de enfermagem à criança num projeto de integração docente assistencial: experiência de implantação. Acta Paul Enferm. 2002;15(2):79-85.

14 M inistério da Saúde (BR), Conselho Nacional de Saúde, Comitê Nacional de Ética em Pesquisa em Seres Humanos. Resolução 196, de 10 de outubro de 1996: diretrizes e normas regulamentadoras de pesquisa envolvendo seres humanos. Brasília (DF); 1996.

$15 \mathrm{H}$ anna B. A dolescent parenthood: a costly mistake or a search of love? Reprod Health M atters. 2001;9 (17):101-7.

16 Quinlivan JA. T eenagers who plan parenthood. Sex Health. 2004;1(4):201-8.

17 Condon JT, D onovan J, Corkindale CJ. A dolescent's attitudes and beliefs about pregnancy and parenthood: results from a school-based based intervention program. Int J AdolescYouth. 2001; 9:245-56

18 Burak R . T eenagesexual behaviour: attitudes towards and declared sexual activity. Br J Fam Plann. 1999; 24(4):145-8.

19 Bergamaschi SF F, Praça NS. Vivência da puérperaadolescente no cuidado do recém-nascido, no domicílio. Rev Esc Enferm U SP. 2008;42(3):45460.

20 Folle E, G eib LT C. Representações sociais das primíparas adolescentes sobre o cuidado mater no ao recém-nascido. Rev L atino-Am E nfermagem. 2004; 12(2):183-90.

Recebido em: 21/ 06/ 2009

A provado em: 21/ 12/ 2009

\section{Endereço da autora / Dirección del autor / Author's address:}

Paula Rosenberg de Andrade

Rua Pensilvânia, 520, ap. 32, Brooklin

04564-001, São Paulo, SP

E-mail: paularandrade@uol.com.br 